\title{
Post-embryonic development of Camallanus cotti (Nematoda: Camallanidae), with emphasis on growth of some taxonomically important somatic characters
}

\author{
Arne Levsen ${ }^{1,2,3}$ and Bjørn Berland ${ }^{1}$ \\ ${ }^{1}$ Department of Zoology, University of Bergen, Allégaten 41, N-5007 Bergen, Norway; \\ ${ }^{2}$ Department of Agriculture and Natural Sciences, Hedmark University College, Blæstad, N-2322 Ridabu, Norway; \\ ${ }^{3}$ Institute of Nutrition, Directorate of Fisheries, P.O. Box 185, N-5804 Bergen, Norway
}

Key words: Nematoda, Camallanus cotti, post-embryonic development, post-maturational growth, taxonomy

\begin{abstract}
In this paper, the quantitative post-embryonic development of the Asian freshwater fish nematode Camallanus cotti Fujita, 1927, is described. Larval and adult morphometrics were obtained by following the parasite's life cycle experimentally using copepods Macrocyclops albidus (Jurine) as intermediate host and guppies Poecilia reticulata (Peters), southern platyfish Xiphophorus maculatus (Günther) and paradise fish Macropodus opercularis (L.) as definitive host. Additionally, adult worms were obtained from heavily infected paradise fish imported from Singapore. It is suggested that the gradual change in proportions of the worm's somatic body parts reflects the specific ecological role of each developmental stage. The free-living infective firststage larva seems to be adapted for transmission, as indicated by its relatively long tail, designed to generate host-attracting movements, and its non-functional intestine. The second- and third-stage larvae from the copepod intermediate host seem mainly to invest in trophic functionality, i.e., the development of the buccal capsule and the oesophagus, which are crucial structures for the worm's successful establishment in the definitive fish host. Once in the fish intestine, the larvae enter a period of considerable growth. After the fourth (i.e., last) moult, a $72 \%$ increase in average female body length occurs. This is accompanied by doubling the average vulva-tail tip distance and the average tail length. The length of the female hind body expands in an accelerating allometric fashion, and seems to be closely linked to the posterior-wards expansion of the uterus. In the males however, growth seems to cease after the final moult. We conclude that female post-maturational body size, but especially the length of the hind body and the tail, are closely related to reproductive state, i.e., the developmental stage of the offspring in the uterus, and, probably, the worms' age. Any future taxonomical studies of camallanids in general, and C. cotti in particular, should thus be aware of the reproductive state of the females used.
\end{abstract}

The general nematode life cycle comprises six stages: egg, first-stage $\left(\mathrm{L}_{1}\right)$ to fourth-stage $\left(\mathrm{L}_{4}\right)$ larva and the adult stage, with four moults separating the five vermiform stages. Growth by definition (i.e., the net input of energy to increase body mass) occurs mainly between the moults (Bird 1971, Wharton 1986). However, according to Anderson (1992) and Malakhov (1994) a significant increase in overall body size in zooparasitic nematodes takes place in the last (i.e., adult) stage, which is not followed by further moulting. Malakhov (1994) also points out that in some groups, the overall increase in body mass during the adult stage may be $50-80 \%$, or even up to $99 \%$ as seen in Ascaris, Ascaridia and Syngamus. However, there are relatively few studies that deal with post-maturational growth in non-ascaridid and non-strongylid nematodes, and, in general, quantitative studies of nematode development and growth have been neglected (Malakhov 1994).

In this paper, we describe the quantitative postembryonic development of Camallanus cotti Fujita, 1927. This spirurid freshwater fish nematode is naturally distributed in East, South and Southeast Asia. During the past 3-4 decades it has been disseminated to Europe, North America, Hawaii and Australia, mainly due to the extensive ornamental fish trade (Font and Tate 1994). Camallanus cotti, like all camallanids, is ovoviviparous with mature females releasing motile infective larvae. Many camallanid species have been studied with regard to life cycle as well as larval and adult morphology but little is known about their postembryonic development in general and the adult stage in particular. With regards to the post-maturational growth of some conspicuous somatic features, and their taxonomical significance, few, if any, camallanid species have been studied in detail to date. Thus, the aim of the present study is to investigate $C$. cotti's post-embryonic development with emphasis on a) the change in proportion and restructuring of various somatic body parts, $b$ ) the post-maturational growth of the female reproductive system relative to body size, and c) the variability of some taxonomically important characters in postmaturational adults.

\section{MATERIALS AND METHODS}

Data on C. cotti's larval morphometry were taken from Levsen and Berland (2002), who studied the parasite's development and morphogenesis using copepods Macro- 
cyclops albidus (Jurine) and guppies Poecilia reticulata (Peters) as experimental intermediate and definitive host, respectively. Adult worms were obtained from cultured southern platyfish Xiphophorus maculatus (Günther) and paradise fish Macropodus opercularis (L.). Both species were imported from Singapore and used in an infection trial studying the parasite's success at establishing in fish. Additionally, adult worms were obtained from heavily infected, cultured paradise fish originating in Singapore and delivered to our laboratory by a local ornamental fish dealer in Bergen, Norway. The fish length ranges were $23-31 \mathrm{~mm}$ in platyfish $(\mathrm{n}=10), 40-42 \mathrm{~mm}$ in paradise fish from the infection trial $(\mathrm{n}=4)$ and $59-63 \mathrm{~mm}$ in paradise fish received from the fish dealer $(n=3)$. The age of the worms obtained from the latter, herein referred to as indirectly imported paradise fish, was not known. However, based on their reproductive state, the adult females could be divided into two distinct groups: 1) the females from the infection trial were first-time reproducers, herein called early-reproducing-state (ERS) females, and had exclusively eggs (at early cleavage stage) in the uterus, and 2) the females from the indirectly imported paradise fish, herein called advanced-reproducingstate (ARS) females, had mainly larvae in the uterus. Males were regarded as adults and thus sexually functional, when both spicules were present and fully developed. For measuring larval morphometry, the specimens were prepared as follows: first- and second-stage larvae $\left(\mathrm{L}_{1}\right.$ and $\left.\mathrm{L}_{2}\right)$ were killed by brief heating in water, fixed in glycerol-ethanol and measured as temporary wet mounts. Third- and fourth-stage larvae $\left(\mathrm{L}_{3}\right.$ and $\mathrm{L}_{4}$ ) and the adults were fixed in Berland's fluid (95 parts glacial acetic acid +5 parts undiluted formalin, see Gibson 1979), cleared in glycerol and measured as temporary wet mounts. All measurements are given in $\mu \mathrm{m}$. The following characters were chosen for analysis of growth due to their distinctness at an early developmental stage and/or taxonomical significance: total body length (BL), width at midbody (BW), total oesophagus length (OL), muscular/glandular oesophagus ratio (RO), buccal capsule length (CL), tail length (TL) (i.e., anus-tail tip distance), vulva-tail tip distance (VT) in females, and spicule lengths (SL) in males.

The relationship between adult worm length, separately for ERS females, ARS females and males, and fish host length, was analysed using Pearson correlation. For analysis of postembryonic growth the proportions of the actual characters to body length are expressed as relative measurements, i.e., the percentage of the length of the actual character to BL. A one way ANOVA, followed by a Tukey HSD post hoc test, was performed in order to determine the significance level of the differences in mean values of relative OL, TL and CL, and RO, among $C$. cotti's post-embryonic developmental stages. Pearson correlation was used to analyse the relationship between absolute $\mathrm{BL}$ and the absolute values of $\mathrm{BW}, \mathrm{OL}, \mathrm{CL}$, $\mathrm{TL}$ and VT, respectively, in post-maturational female worms. Pearson correlation was also used to analyse the relationship between male absolute BL and a) absolute length of either spicule, and b) ratio left/right SL. In order to equalise variances and to linearise allometric relationships, the values were logarithm transformed. The specific change in proportion of the characters was calculated using the regression equation $\mathrm{y}=\mathrm{a}+\mathrm{bx}$, where $\mathrm{x}=\log (\mathrm{BL}), \mathrm{y}$ is the logarithm of the character to be related, a represents the y intercept, while the slope $b$ represents an estimate of allometry. At $b>1$ the $y$ character increases relatively faster to $\mathrm{BL}$ (accelerating allometric relationship), while at $0<\mathrm{b}<1$ the y character increases relatively slower to $\mathrm{BL}$ (decelerating allometric relationship). At $b=1$ linear relationship (isometry) is maintained between the y character and BL during development (Gould 1966). The significance level was set at 0.05 .

\section{RESULTS}

The nematode was identified as Camallanus cotti as the adult morphology is in accordance with the descriptions given by Moravec and Nagasawa (1989) and Rigby et al. (1997). The worms' adult body length was not related to host body length, neither in ERS females, ARS females nor males ( $p>0.05$ for all groups).

\section{Post-embryonic development}

Camallanus cotti's post-embryonic developmental pattern, expressed as the change in relative oesophagus length, muscular/glandular oesophagus ratio, relative tail length and relative buccal capsule length from $\mathrm{L}_{1}$ ex utero to the adult stage, is shown in Figs. 1, 2. The relative oesophagus length is greatest in early $\mathrm{L}_{3}$, comprising $40 \pm 2.5 \%$ of the total body length, while the lowest value, $14 \pm 1 \%$, is seen in the ARS females. A considerable increase in relative oesophagus length occurs during $\mathrm{L}_{2}$, i.e., between the first and second moult when the muscular and glandular portions differentiate. Then, after a gradual decline in late $\mathrm{L}_{3}$ to ERS females, the relative oesophagus length falls considerably during further post-maturational development in female worms. In adult males, the relative oesophagus length is about the same as in ERS females. One way ANOVA $\left(\mathrm{F}_{1,84}=9570,88 ; \mathrm{p}<0.01\right)$ and Tukey HSD post hoc comparisons revealed significant differences in mean values of relative $\mathrm{OL}$ among free $\mathrm{L}_{1}$ and $\mathrm{L}_{1}$ from copepods $(\mathrm{p}<0.03), \mathrm{L}_{1}$ from copepods and early $\mathrm{L}_{2}(\mathrm{p}<0.03)$, late $\mathrm{L}_{2}$ and $\mathrm{L}_{3}$ from copepods $(\mathrm{p}<0.01), \mathrm{L}_{3}$ from copepods and $\mathrm{L}_{3}$ from fish $(\mathrm{p}<0.02), \mathrm{L}_{3}$ from fish and female $\mathrm{L}_{4}(\mathrm{p}<0.01)$, and ERS- and ARS females $(\mathrm{p}<0.01)$.

Shortly before the second moult, when both parts of the oesophagus seem to be fully differentiated, the muscular/glandular oesophagus ratio (RO) is 1.3-1.4 : 1. During $\mathrm{L}_{3}$ and $\mathrm{L}_{4}$ the ratio does not change significantly before dropping to less than 1 in adults, i.e., it has changed in favour of the glandular part. One way ANOVA $\left(\mathrm{F}_{1,65}=6235,89 ; \mathrm{p}<0.01\right)$ and Tukey HSD post hoc comparisons revealed significant differences in mean values of RO among early $\mathrm{L}_{2}$ and late $\mathrm{L}_{2}$ $(\mathrm{p}<0.01)$, late $\mathrm{L}_{2}$ and $\mathrm{L}_{3}$ from copepods $(\mathrm{p}<0.002)$, late $\mathrm{L}_{2}$ and female $\mathrm{L}_{4}(\mathrm{p}<0.01)$, and early $\mathrm{L}_{4}$ and ERS females $(\mathrm{p}<0.003)$.

The relative tail length is greatest during $\mathrm{L}_{1}$ and early $\mathrm{L}_{2}$, comprising $25-30 \%$ of the total body length. It decreases considerably between the first and second 


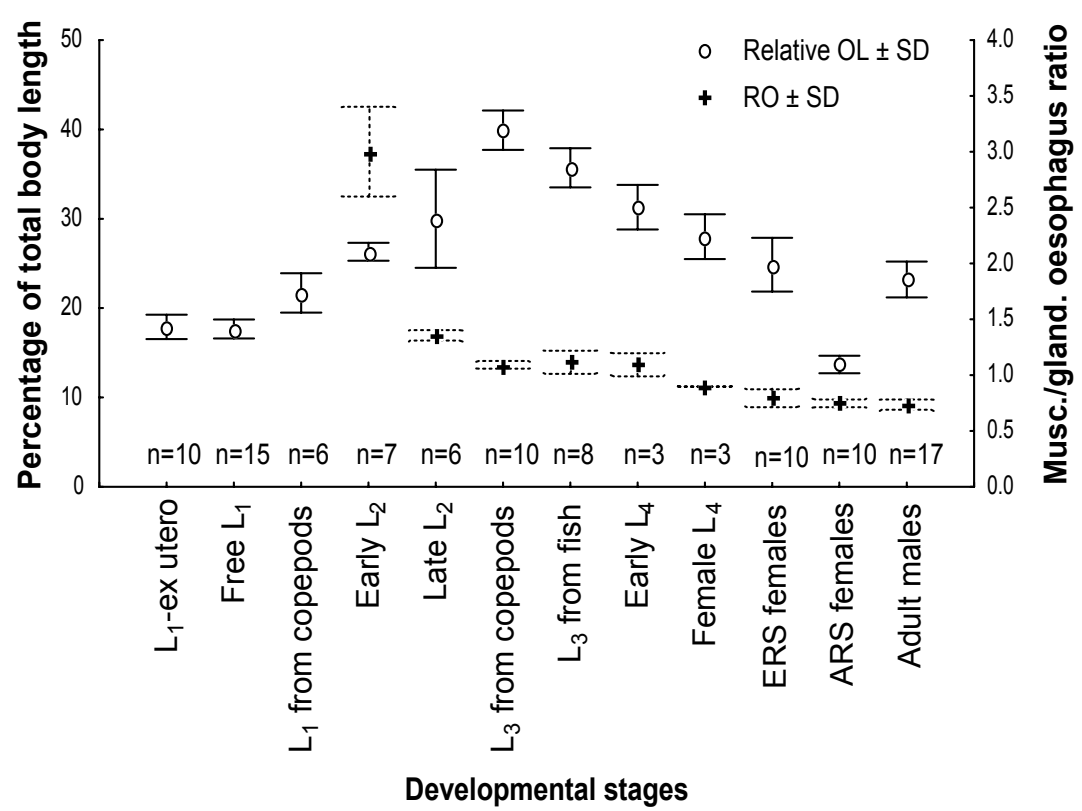

Fig. 1. Relative oesophagus length (mean $\pm \mathrm{SD}$ ) and muscular/glandular oesophagus ratio (mean $\pm \mathrm{SD}$ ), in $\mathrm{L}_{1}$ ex utero to adults of Camallanus cotti. Abbreviations: SD - standard deviation, OL - oesophagus length, RO - muscular/glandular oesophagus ratio, ERS - early reproducing state, ARS - advanced reproducing state.

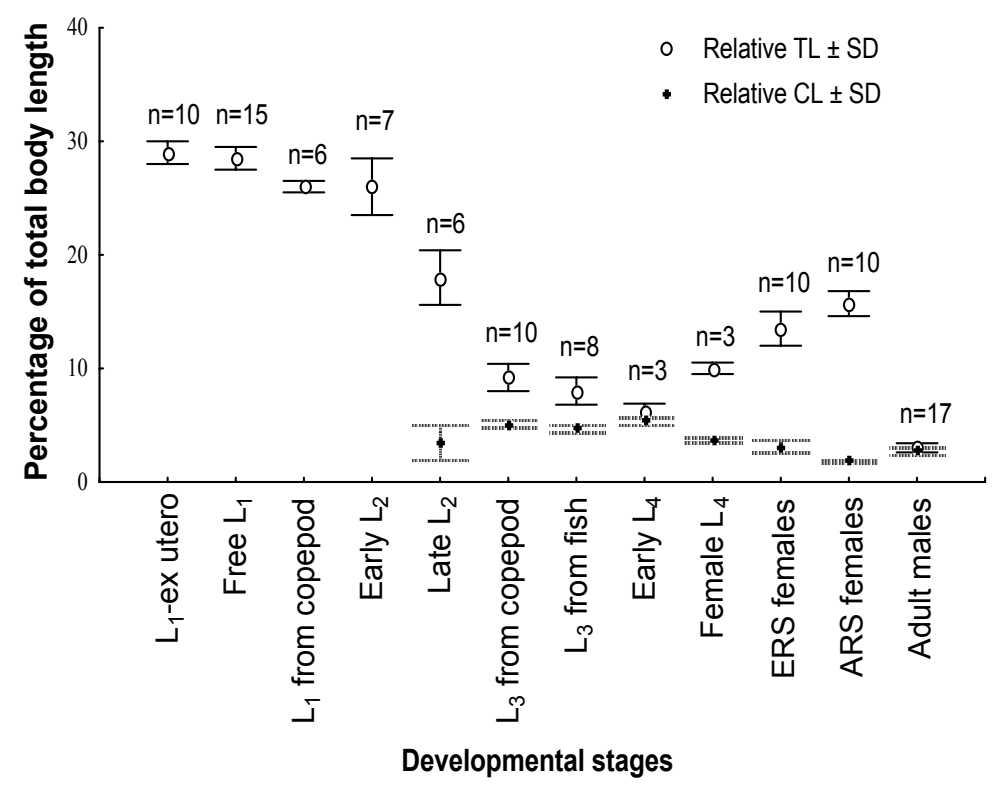

Fig. 2. Relative tail length (mean $\pm \mathrm{SD}$ ) and relative buccal capsule length (mean $\pm \mathrm{SD}$ ), in $\mathrm{L}_{1}$ ex utero to adults of Camallanus cotti. Abbreviations: SD - standard deviation, TL - tail length, CL - buccal capsule length, ERS - early reproducing state, ARS advanced reproducing state.

moult and varies between $7-11 \%$ and $6-7 \%$ in $\mathrm{L}_{3}$ and early $\mathrm{L}_{4}$, respectively. The comparatively large increase in body length in female $\mathrm{L}_{4}$ and post-maturational females is accompanied by a gradual increase in relative tail length, ranging from $10-11 \%$ in female $\mathrm{L}_{4}$ to 14 $17 \%$ in ARS females. In adult males, however, the relative tail length remains small, comprising $3.0 \pm$ $0.4 \%$ of the total body length. One way ANOVA ( $\mathrm{F}_{1,84}$
$=10147,48 ; \mathrm{p}<0.01)$ and Tukey HSD post hoc comparisons revealed significant differences in mean values of relative $T L$ among free $L_{1}$ and $L_{1}$ from copepods $(p<0.002)$, early $\mathrm{L}_{2}$ and late $\mathrm{L}_{2}(\mathrm{p}<0.01)$, late $\mathrm{L}_{2}$ and $\mathrm{L}_{3}$ from copepods $(\mathrm{p}<0.01), \mathrm{L}_{3}$ from copepods and early $\mathrm{L}_{4}(\mathrm{p}<0.04)$, early $\mathrm{L}_{4}$ and female $\mathrm{L}_{4}$ $(\mathrm{p}<0.01)$, female $\mathrm{L}_{4}$ and ERS females $(\mathrm{p}<0.02)$, and ERS- and ARS females $(p<0.007)$. 


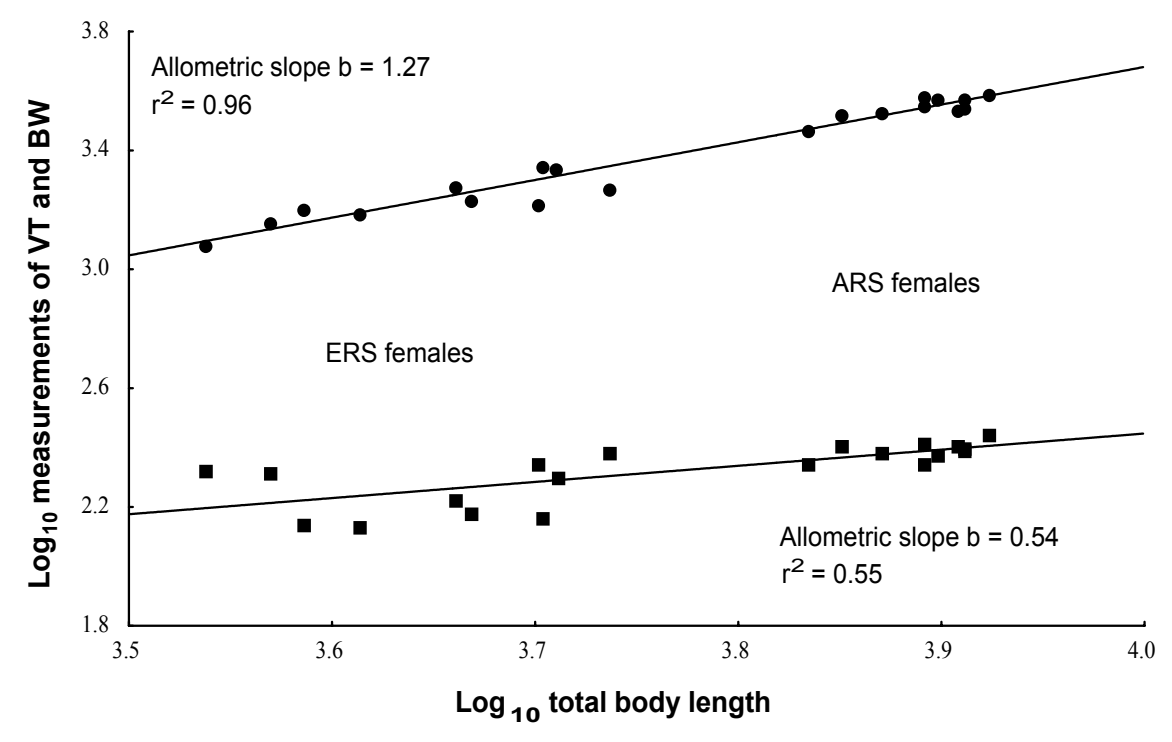

Fig. 3. Allometric relationship between vulva-tail tip distance $(\mathrm{VT})(\bullet)$, body width $(\mathrm{BW})(\mathbf{\bullet})$, and total body length, in postmaturational females of Camallanus cotti. Abbreviations: ERS - early reproducing state, ARS - advanced reproducing state.

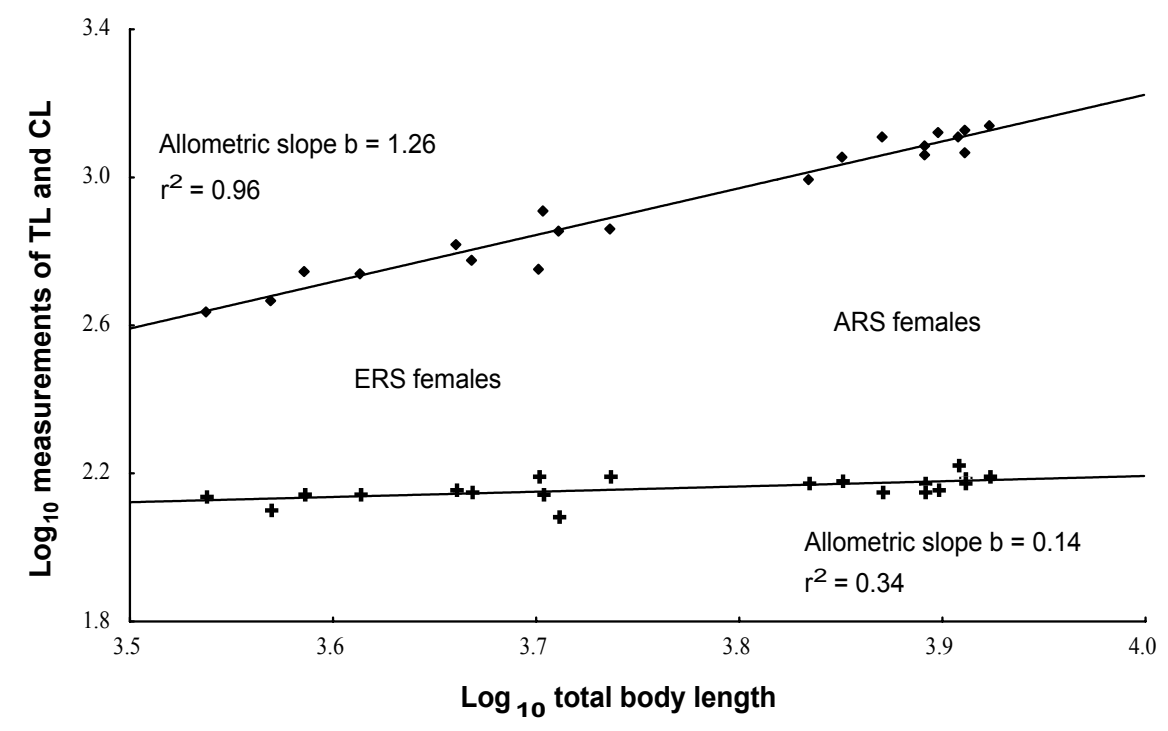

Fig. 4. Allometric relationship between tail length $(\mathrm{TL})(\bullet)$, length of buccal capsule $(\mathrm{CL})(+)$, and total body length, in postmaturational females of Camallanus cotti. Abbreviations: ERS - early reproducing state, ARS - advanced reproducing state.

The buccal capsule emerges during $\mathrm{L}_{2}$ and seems to be fully functional as a holdfast organ in $\mathrm{L}_{3}$ from the fish host, comprising $4.8 \pm 0.3 \%$ of the total body length. A gradual decrease of the relative buccal capsule length occurs during $\mathrm{L}_{4}$ and female adults, reaching its minimum 1.8-2.2\% in ARS females. In adult males, the buccal capsule comprises $2.4-3.5 \%$ of the total body length, which is about the same as in the ERS females. One way ANOVA $\left(\mathrm{F}_{1,59}=2667,30 ; \mathrm{p}<0.01\right)$ and Tukey HSD post hoc comparisons revealed significant differences in mean values of relative $C L$ among late $\mathrm{L}_{2}$ and $\mathrm{L}_{3}$ from copepods $(\mathrm{p}<0.01)$, early $\mathrm{L}_{4}$ and female $\mathrm{L}_{4}$ $(p<0.003)$, early $\mathrm{L}_{4}$ and males $(\mathrm{p}<0.01)$, and ERSand ARS females $(\mathrm{p}<0.01)$. 


\section{Post-maturational growth}

Considerable increase in absolute total body length ( $72 \%$ on average) occurs between the ERS- and the ARS females, i.e., after the last moult (Table 1). This is accompanied by a $36 \%$ increase in average body width, $101 \%$ in average tail length and $104 \%$ in average length of the vulva-tail tip distance. The increase in total body length seems mainly to be due to the large expansion of the female hind body, as evident by more than a doubling of the average tail length and the vulva-tail tip distance between the ERS- and ARS females. Additionally, there are significantly accelerating allometric relationships between vulva-tail tip distance and total body length $\left(\mathrm{b}=1.27, \mathrm{r}^{2}=0.96, \mathrm{p}<0.01\right)$, and tail length and total body length $\left(b=1.26, r^{2}=0.96, p<\right.$ 0.01) (Figs. 3, 4). Significantly decelerating allometric relationships were found between body width and total body length $\left(\mathrm{b}=0.54, \mathrm{r}^{2}=0.55, \mathrm{p}<0.01\right)$, and buccal capsule length and total body length $\left(b=0.14, r^{2}=0.34\right.$, $\mathrm{p}<0.01$ ) (Figs. 3, 4). Total length of oesophagus and total body length, on the other hand, were not significantly related.

In post-maturational males of $C$. cotti, no significant increase in either total body length or body width was found. Thus, shortly after the final moult, further growth in overall body size seems to cease. Additionally, there was no significant relationship between total body length and length of either left or right spicules, nor between total body length and the ratio left/right spicule (all $\mathrm{p}>0.05$ ).

\section{Adult morphometric variability}

Table 1 shows some comparable morphometrics of C. cotti, based on the present findings and those of Moravec and Nagasawa (1989) and Rigby et al. (1997). Comparison of the findings of Moravec and Nagasawa (1989) and the present study reveals differences between female body length (females with larvae in the uterus in both studies), apex-nerve ring distance in males and females, apex-excretory pore distance in males, the length of the buccal capsule in males and females, and, especially, the female tail length and the vulva-tail tip distance. The only difference between the present results and those of Rigby et al. (1997) is found in the vulva-tail tip distance. Especially in the males there is a high degree of overlap of most measurements in both studies.

\section{DISCUSSION}

The present study has shown that the gradual change in proportions of the body parts and organs during Camallanus cotti's post-embryonic development may reflect the specific ecological role of each developmental stage. Thus, the relatively long tail and correspondingly short oesophagus of the free-living infective $\mathrm{L}_{1}$ seem to be adaptations for enhancing transmission to the intermediate host. Immediately after birth, the free $L_{1}$ attach themselves to the substrate by their tail tip and start to undulate vigorously in a spirallike manner in order to attract a host (Levsen 2001). No increase in body size occurs during this stage and the alimentary tract seems to be non-functional; the larvae probably rely on lipid reserves as their main energy source (Croll and Matthews 1973, Tielens 1994). The slight increase in relative oesophagus length and slight decrease in relative tail length in the $L_{1}$ from the copepod intermediate host may be initialising events of the forthcoming first moult. During $\mathrm{L}_{2}$, major development takes place as reflected by increasing body size, decreasing relative tail length, appearance of the buccal capsule and differentiation of the oesophagus into muscular and glandular parts. The increase in length of the glandular portion relative to the muscular one from late $L_{2}$ to the adult stage may be due to a gradually increasing importance of the glandular oesophagus as an endocrine secretory organ (Törnquist 1931). Thus, $C$. cotti's $\mathrm{L}_{2}$ represents a transitional stage between the infective free-living first stage, primarily adapted for transmission, and the third stage in which the structures that are crucial for attachment and feeding, i.e., the buccal capsule and the oesophagus, are becoming functional; their relative size being largest in this stage. This is further reflected by the considerable and comparatively rapid growth in overall body size in $\mathrm{L}_{3}$ from the definitive fish host, which actively feeds on host blood or tissue fluid (Stumpp 1975, Levsen 2001). The larval stages that develop in the copepod intermediate host do not increase in body size to the same extent as in the definitive fish host. Thus, during $C$. cotti's development in the copepod, the main investment seems to be in trophic functionality, i.e., the development of the attachment organ and the alimentary tract, rather than increasing body size. The $\mathrm{L}_{3}$ thus represents a critical stage in the development of those structures that are crucial for the worm's success at establishing in the definitive fish host.

In females of the late $\mathrm{L}_{4}$ and the adult stage, the large increase in body size seems to be closely linked to the growth and development of the reproductive system. The significantly accelerating allometric increase in length of the vulva-tail tip distance and the tail of postmaturational females implies that the hind body grows relatively faster than the other body parts. In the ARS females, the uterus extends into the pseudocoel of the tail, almost to its end. The increase in length of the female hind body, and thus the tail, seems to be linked to the increase in length of the uterus. Whether or not this is related to fecundity and fitness remains unclear. However, whatever the purpose, the degree to which the uterus may increase in length is restricted by the ability of the cuticle to expand as no further moulting occurs. One would expect the cuticle to become stretched and thinner during post-maturational development but, according to Bird (1971), the nematode cuticle is capable of considerable growth between moults and 
Table 1. Morphometrics of Camallanus cotti Fujita, 1927 adult males and females according to the present study, Moravec and Nagasawa (1989) and Rigby et al. (1997) (all measurements in $\mu \mathrm{m}$ ).

\begin{tabular}{|c|c|c|c|c|c|c|c|}
\hline Authors & \multicolumn{3}{|l|}{ Present study } & \multicolumn{2}{|c|}{$\begin{array}{l}\text { Moravec and Nagasawa } \\
\text { (1989) }\end{array}$} & \multicolumn{2}{|l|}{ Rigby et al. (1997) } \\
\hline Host origin /locality & \multicolumn{3}{|c|}{ Cultured ornamental fish imported from Singapore } & \multicolumn{2}{|c|}{ Lake Biwa, Honshu, Japan } & \multicolumn{2}{|c|}{ Hakalau Stream, Hakalau, Hawaii } \\
\hline Date of sampling & \multicolumn{3}{|l|}{ March - June 1997} & \multicolumn{2}{|l|}{ February 1980} & \multicolumn{2}{|l|}{ December 1995} \\
\hline Fish host species & Xiphophorus macu & ünther) and $\mathrm{Mact}$ & Is opercularis (L.) & Cottus reinii & ilgendorf) & Poecilia reticulatc & eters) \\
\hline Reproductive state/Sex of parasite & ERS females ${ }^{1}$ & ARS females ${ }^{2}$ & Males $^{3}$ & Females & Males & Females & Males \\
\hline Maturity state of offspring in uterus & Eggs only & Mostly larvae & - & Larvae only & - & Larvae or eggs & - \\
\hline Fixative used & Berland's fluid & Berland's fluid & Berland's fluid & $70 \%$ ethanol & $70 \%$ ethanol & Berland's fluid & Berland's fluid \\
\hline $\mathrm{n}$ & 10 & 10 & 17 & 10 & 10 & 10 & 10 \\
\hline Body length (BL) & $\begin{array}{c}3449-5450 \\
(4502 \pm 685)\end{array}$ & $\begin{array}{c}6830-8380 \\
(7750 \pm 497)\end{array}$ & $\begin{array}{c}2820-3897 \\
(3376 \pm 282)\end{array}$ & $5110-7300^{4}$ & $2770-4050^{4}$ & $\begin{array}{c}3615-9605 \\
(6435 \pm 2431)\end{array}$ & $\begin{array}{c}2539-4565 \\
(3712 \pm 708)\end{array}$ \\
\hline Body width (BW) & $\begin{array}{c}135-241 \\
(182 \pm 39)\end{array}$ & $\begin{array}{c}223-279 \\
(247 \pm 17)\end{array}$ & $\begin{array}{c}128-187 \\
(142 \pm 15)\end{array}$ & $231-313$ & $136-190$ & $\begin{array}{c}137-440 \\
(268 \pm 97)\end{array}$ & $\begin{array}{c}125-221 \\
(173 \pm 32)\end{array}$ \\
\hline Apex-nerve ring distance (AR) & $\begin{array}{c}185-249 \\
(218 \pm 20)\end{array}$ & $\begin{array}{c}205-260 \\
(229 \pm 18)\end{array}$ & $\begin{array}{c}149-171 \\
(162 \pm 8)\end{array}$ & $258-272$ & $180-186$ & $\begin{array}{c}197-240 \\
(217 \pm 17)\end{array}$ & $\begin{array}{c}146-175 \\
(163 \pm 11)\end{array}$ \\
\hline Apex-excretory pore distance (AP) & $\begin{array}{c}249-357 \\
(299 \pm 36)\end{array}$ & $\begin{array}{c}298-360 \\
(319 \pm 20)\end{array}$ & $\begin{array}{l}212-238 \\
(227 \pm 9)\end{array}$ & $299-367$ & $270-273$ & $\begin{array}{c}222-372 \\
(302 \pm 55)\end{array}$ & $\begin{array}{c}188-306 \\
(229 \pm 36)\end{array}$ \\
\hline Buccal capsule length (CL) & $\begin{array}{c}122-157 \\
(140 \pm 11)\end{array}$ & $\begin{array}{c}141-167 \\
(150 \pm 8)\end{array}$ & $\begin{array}{c}82-102 \\
(94 \pm 5)\end{array}$ & $159-165$ & $99-105$ & $\begin{array}{c}114-149 \\
(136 \pm 11)\end{array}$ & $\begin{array}{l}82-101 \\
(93 \pm 6)\end{array}$ \\
\hline Tail length (TL) & $\begin{array}{c}434-810 \\
(609 \pm 121)\end{array}$ & $\begin{array}{c}980-1370 \\
(1224 \pm 120)\end{array}$ & $\begin{array}{c}86-125 \\
(99 \pm 11)\end{array}$ & $816-966$ & $108-123$ & $\begin{array}{c}587-1564 \\
(1002 \pm 319)\end{array}$ & $\begin{array}{c}75-128 \\
(105 \pm 16)\end{array}$ \\
\hline Vulva-tail tip distance (VT) & $\begin{array}{c}1199-2230 \\
(1727 \pm 322)\end{array}$ & $\begin{array}{c}2940-3890 \\
(3520 \pm 282)\end{array}$ & - & $2270-3060$ & - & $2827^{5}$ (mean) & - \\
\hline
\end{tabular}

ERS - early reproducing state; ARS - advanced reproducing state; ${ }^{1} \mathrm{n}=7$ from platyfish, $\mathrm{n}=3$ from paradise fish from infection trial; ${ }^{2} \mathrm{n}=10$ from indirectly imported paradise fish; ${ }^{3} \mathrm{n}=6$ from platyfish, $\mathrm{n}=2$ from paradise fish from infection trial, $\mathrm{n}=9$ from indirectly imported paradise fish; ${ }^{4}$ means and standard deviations are not provided for any measurements; ${ }^{5}$ calculated by us based on the mean values of the body length and vulva-apex distance provided by the authors 
after the last moult. In $C$. cotti females, there is a significantly decelerating allometric relationship between body width and total body length (Fig. 3) but an accelerating allometric increase of the hind body. Thus, the cuticle of the hind body seems mainly to expand longitudinally. This pattern indicates that the cuticle expands by stretching rather than growth in the strict sense. The uterus, on the other hand, is a cellular sacklike organ. It is commonly accepted that nematodes, in general, have somatic cell constancy. If correct, the increase in length of the uterus in $C$. cotti females probably involves hypertrophy, i.e., an increase in cell volume, and, again, not growth by definition. Based on the post-maturational increase in body size in female adults, which appears to be closely related to their reproductive state (i.e., the developmental stage of the offspring in the uterus) it seems likely that female body length is proportional to age.

The males of $C$. cotti, on the other hand, are smaller than the females and apparently do not grow significantly after reaching sexual maturity. In contrast to the mature and gravid females, the posterior body does not increase in size, but remains short. As sperm are less costly to produce than eggs and larvae, they apparently do not invest in increased body size, but may spend more energy in searching for and copulating with females.

It has long been recognised that the external body dimensions in adult nematodes may vary considerably with, for example, parasite age, host size, and climate/locality (Chitwood 1957). Comparison of the present data on $C$. cotti's adult morphometry with those of Moravec and Nagasawa (1989) and Rigby et al. (1997) supports this axiom: Moravec and Nagasawa (1989) investigated C. cotti from the sculpin Cottus reinii (Hilgendorf) from the type locality (Lake Biwa, Japan), Rigby et al. (1997) studied worms from a Hawaiian population introduced along with their poeciliid fish hosts, while the present study is entirely based on worms from cultured ornamental fish originating in Southeast Asia. There are apparently no morphological differences between $C$. cotti specimens from these three populations and there is no detectable effect of the fixative used in each study. Thus, the morphometric discrepancies between the specimens from the type locality and those from the present study may be due to different climatic (Lake Biwa is a subtropical habitat with water temperatures around $7.5^{\circ} \mathrm{C}$ during February, which was the sampling month) and/or host-related conditions. Hence, at least two different morphometric strains of $C$. cotti seem to exist where each is characterised by specific and comparatively narrow range in adult body size, length of the female hind body, and the tail.

Rigby et al. (1997), on the other hand, were measuring female worms of different reproductive states; i.e., with either eggs or larvae in the uterus, which may explain the wide range in external body dimensions (Table 1). It seems doubtful whether the measuring of females ranging widely in body size is of any taxonomic value, as the present findings show that several important characters, especially the body length, body width, vulva-tail tip distance and tail length seem to be closely related to and dependent on female reproductive state. Hence, the present findings indicate that any future taxonomic studies of $C$. cotti should be aware of the reproductive state of the individual female worms used. Moreover, as far as we are aware, no other camallanid species have been studied as to their postmaturational growth pattern. However, all known camallanids are ovoviviparous with a similar postembryonic development (Anderson 1992). Thus, it is possible that adult females of other camallanid species may increase considerably in body size after the last moult, as well. Hence, based on the present findings we suggest that when identifying, describing or redescribing any camallanid nematode, the reproductive state of the female worms should be taken into consideration.

Acknowledgements. This study was financially supported by the Norwegian Directorate for Nature Management. We thank Arne Skorping and Per J. Jakobsen for valuable comments on the manuscript, and Olav Askeland for technical assistance.

\section{REFERENCES}

ANDERSON R.C. 1992: Nematode Parasites of Vertebrates. Their Development and Transmission. CAB International, Wallingford, UK, $578 \mathrm{pp}$.

BIRD A.F. 1971: The Structure of Nematodes. Academic Press, New York, 318 pp.

CHITWOOD M.B. 1957: Intraspecific variation in parasitic nematodes. Syst. Zool. 6: 19-23.

CROLL N.A., MATTHEWS B.E. 1973: Activity, aging and penetration of hookworm larvae. Parasitology 66: 279289.

FONT W.F., TATE D.C. 1994: Helminth parasites of native Hawaiian freshwater fishes: an example of extreme ecological isolation. J. Parasitol. 80: 682-688.
GIBSON D.I. 1979: Materials and methods in alphataxonomy. Parasitology 79: xxxvi.

GOULD S.J. 1966: Allometry and size in ontogeny and phylogeny. Biol. Rev. 41: 587-640.

LEVSEN A. 2001: Transmission ecology and larval behaviour of Camallanus cotti (Nematoda, Camallanidae) under aquarium conditions. Aquar. Sci. Conserv. 3: 315-325.

LEVSEN A., BERLAND B. 2002: The development and morphogenesis of Camallanus cotti Fujita, 1927 (Nematoda: Camallanidae), with notes on its phylogeny and definitive host range. Syst. Parasitol. 53: 29-38. 
MALAKHOV V.V. 1994: Nematodes. Structure, Development, Classification, and Phylogeny. Smithsonian Institution Press, Washington and London, $286 \mathrm{pp}$.

MORAVEC F., NAGASAWA K. 1989: Observations on some nematodes parasitic in Japanese freshwater fishes. Folia Parasitol. 36: 127-141.

RIGBY M.C., FONT W.F., DEARDORFF T.L. 1997: Redescription of Camallanus cotti Fujita, 1927 (Nematoda: Camallanidae) from Hawai'i. J. Parasitol. 83: 1161-1164.

STUMPP M. 1975: Untersuchungen zur Morphologie und Biologie von Camallanus cotti (Fujita, 1927). Z. Parasitenkd. 46: 277-290.

Received 17 August 2001
TIELENS A.G.M. 1994: Energy generation in parasitic helminths. Parasitol. Today 10: 346-352.

TÖRNQUIST N. 1931: Die Nematodenfamilien Cucullanidae und Camallanidae nebst weiteren Beiträgen zur Kenntnis der Anatomie und Histologie der Nematoden. Göteborgs K. Vetensk.-o. Vitterh.-Samh. Handl. 5. följden, Ser. B, 2: $1-441$.

WHARTON D.A. 1986: A Functional Biology of Nematodes. Beckenham, Croom Helm, 192 pp.

Accepted 29 January 2002 